\title{
Pacemaker risk associated with prophylactic tricuspid annuloplasty: Balancing beneficence and nonmaleficence
}

\author{
Carlos A. Mestres, MD, PhD, and Rakesh M. Suri, MD, DPhil
}

\author{
From the Cleveland Clinic Abu Dhabi Heart and Vascular Institute, Abu Dhabi, United Arab Emirates. \\ Disclosures: Authors have nothing to disclose with regard to commercial support. \\ Received for publication Sept 30, 2015; accepted for publication Oct 1, 2015; available ahead of print Oct 31, \\ 2015 . \\ Address for reprints: Rakesh M. Suri, MD, DPhil, Cleveland Clinic Lerner College of Medicine, Cleveland Clinic \\ Abu Dhabi, PO Box 112412, United Arab Emirates (E-mail: surir@ccf.org). \\ J Thorac Cardiovasc Surg 2016;151:104-5 \\ $0022-5223 / \$ 36.00$ \\ Copyright (C) 2016 by The American Association for Thoracic Surgery \\ http://dx.doi.org/10.1016/j.jtcvs.2015.10.014
}

The incidence of permanent pacemaker implantation (PPM) after heart valve surgery is well recognized in patients undergoing aortic valve replacement $(2 \%-7 \%),{ }^{1}$ isolated mitral valve replacement or repair $(4 \%),{ }^{2,3}$ and tricuspid valve replacement (up to $20 \%$ ). ${ }^{4,5}$ Proposed factors predisposing toward transient or permanent postoperative conduction abnormalities (PCAs) include age, preexisting right or left bundle branch block, preoperative antiarrhythmic drugs, intraoperative hypothermia, and cardiopulmonary bypass duration. Recent evidence indicates that the actual incidence of PCA could approach $35 \%$ to $40 \%$ in certain situations. ${ }^{6}$ Retrospective singleinstitution studies with a varying sample sizes, study designs, and end points suggest that age and duration of cardiopulmonary bypass in particular may influence PPM implantation immediately after surgery. ${ }^{7}$ The anatomic studies of Berdajs and colleagues ${ }^{8}$ identified 2 morphologic variants of the atrioventricular node artery in particular that are closely juxtaposed to the mitral and tricuspid annulus in as many as $58 \%$ of patients, theoretically increasing the risk of postoperative rhythm disturbances after atrioventricular valve surgery (see Central Figure). Importantly, once a PCA has been identified, the appropriate timing of PPM placement remains controversial. Whereas some advocate PPM implantation within 48 hours after surgery, more conservative teams advocate a delay in the decision for as long as 2 to 3 weeks postoperatively.

In this issue of the Journal, Jouan and colleagues ${ }^{9}$ report the incidences of PCA and PPM implantation associated with nonischemic mitral repair or replacement $(36.8 \%)$ with or without concomitant tricuspid annuloplasty. They studied 201 patients, with $88(43.8 \%)$ undergoing combined procedures. Five patients required PPM implantation within the first 3 postoperative months, and 2 underwent late implantation. The freedoms from PPM at 36 months were $99.0 \%$ in the isolated mitral operation group and $94.1 \%$ in the combined mitral and tricuspid population, a statistically significant difference. Jouan and colleagues ${ }^{9}$ concluded that pacemaker risk was

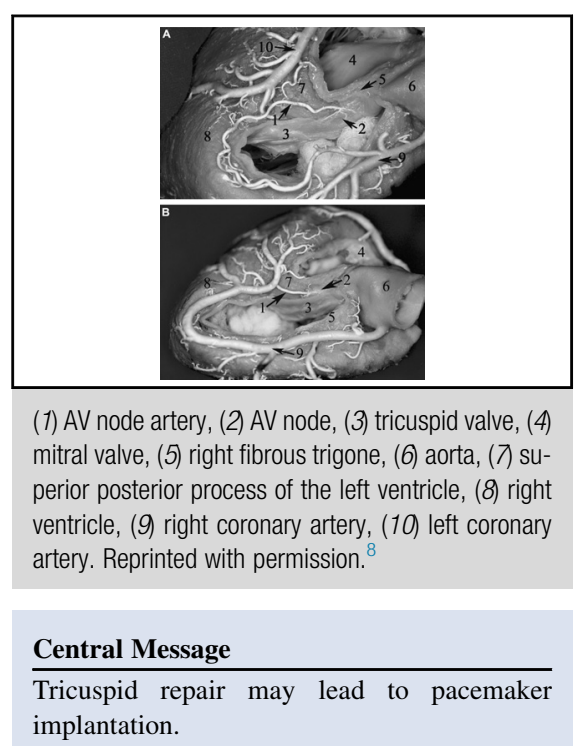

See Article page 99.

See Editorial page 7.

increased by concomitant tricuspid annuloplasty at the time of mitral valve surgery; they also recommended an observation period of as long as 14 days before PPM implantation.

The topic of PPM implantation ${ }^{10}$ after combined mitral and tricuspid valve procedures has been infrequently addressed in the literature to date. Although tricuspid valve annuloplasty is a known risk factor for PCA and has been included in previous prediction models, ${ }^{11}$ this study by Jouan and colleagues ${ }^{9}$ raises several important points worthy of contemplation by mitral surgeons. First, the suggestion of a 2-week period of watchful waiting before a decision is made with regard to PPM implantation is noteworthy. It is of particular relevance in contemporary practice, because delaying discharge of a patient from the hospital while awaiting a decision regarding PPM implantation may impact cost and quality metrics. Second, the role of tricuspid annuloplasty ring shape and rigidity has not been fully elucidated in this report, but it is undoubtedly influential. Third, long-term complications of PPMs, such as right-sided infective endocarditis or pacemaker-induced tricuspid regurgitation, warrant consideration but are still infrequently considered when assessing the risks and benefits of prophylactic tricuspid operations. ${ }^{12}$ 
On the basis of the data presented by Jouan and colleagues, ${ }^{9}$ it may be prudent to reexamine the recent wave of enthusiasm for prophylactic tricuspid annuloplasty, particularly in the setting of trivial to mild tricuspid regurgitation at the time of nonischemic mitral valve surgery. It is certainly ethically important to articulate the risks of an iatrogenic rhythm-based complication to patients during the informed consent process before surgery. Although early correction of degenerative mitral regurgitation has been shown to decrease the incidence of concomitant functional tricuspid regurgitation, ${ }^{13}$ the ability of prophylactic tricuspid annuloplasty to diminish reoperation risk in patients with intact degenerative mitral repair has not been demonstrated with the same scientific rigor. Functional tricuspid repair is rationally indicated at the time of degenerative mitral repair under specific circumstances, such as in the presence of moderate or greater tricuspid regurgitation, right heart failure, pulmonary hypertension, reduced left ventricular function, and organic tricuspid valve disease. ${ }^{14}$ In the absence of these conditions, prophylactic tricuspid repair potentially risking iatrogenic right heart rhythm disturbance leading to PPM implantation is questionable in the modern era, according to work published in this issue of The Journal of Thoracic and Cardiovascular Surgery. The fine balance between performing a procedure to benefit patients and withholding an additional maneuver to avoid harm in the absence of compelling indication is one that appears particularly relevant to this discussion.

\section{References}

1. Schurr UP, Berli J, Berdajs D, Hausler A, Dzemali I, Emmert M, et al. Incidence and risk factor for pacemaker implantation following aortic valve replacement. Interact Cardiovasc Thorac Surg. 2010;11:556-60.
2. Goldman BS, Hill TJ, Weisel RD, Scully HE, Mickleborough LL, Pym J, et al. Permanent pacing after open-heart surgery: acquired heart disease. Pacing Clin Electrophysiol. 1984;7(3 Pt 1):367-71.

3. Meimoun P, Zeghdi R, D'Attelis N, Berrebi A, Braunberger E, Deloche A, et al Frequency, predictors, and consequences of atrioventricular block after mitral valve repair. Am J Cardiol. 2002;89:1062-6.

4. Scully HE, Armstrong CS. Tricuspid valve replacement: fifteen years of experience with mechanical prostheses and bioprostheses. J Thorac Cardiovasc Surg. 1995;109:1035-41.

5. Jökinen JJ, Turpeinen AK, Pitkänen O, Hippeläinen MJ, Hartikainen JE. Pacemaker therapy after tricuspid valve operations: implications on mortality, morbidity and quality of life. Ann Thorac Surg. 2009;87:1806-14.

6. Gordon RS, Ivanov J, Cohen G, Ralph-Edwards A. Permanent cardiac pacing after a cardiac operation: predicting the use of permanent pacemakers. Ann Thorac Surg. 1998;66:1698-704.

7. Lewis JW Jr, Webb CR, Pickard SD, Lehman J, Jacobsen G. The increased need for permanent pacemaker after reoperative cardiac surgery. J Thorac Cardiovasc Surg. 1998;116:74-81.

8. Berdajs D, Schurr UP, Wagner A, Seifert B, Turina MI, Genoni M. Incidence and pathophysiology of atrioventricular block following mitral valve replacement and ring annuloplasty. Eur J Cardiothorac Surg. 2008;34:55-61.

9. Jouan J, Melé A, Florens E, Chatellier G, Carpentier A, Achouh P, et al. Conduction disorders after tricuspid annuloplasty with mitral valve surgery: implications for earlier tricuspid intervention. J Thorac Cardiovasc Surg. 2016;151:99-103.

10. Mestres CA. Discussion of Berdajs D, Schurr UP, Wagner A, Seifert B, Turina MI, Genoni M. Incidence and pathophysiology of atrioventricular block following mitral valve replacement and ring annuloplasty. Eur J Cardiothorac Surg. 2008;34:61.

11. Koplan BA, Stevenson WG, Epstein LM, Aranki SF, Maisel WH Development and validation of a simple risk score to predict the need for permanent pacing after cardiac valve surgery. J Am Coll Cardiol. 2003;41: 795-801.

12. del Río A, Anguera I, Miró JM, Mont L, Fowler VG Jr, Azqueta M, et al Hospital Clínic Endocarditis Study Group. Surgical treatment of pacemaker and defibrillator lead endocarditis: the impact of electrode lead extraction on outcome. Chest. 2003;124:1451-9.

13. Suri RM, Vanoverschelde JL, Grigioni F, Schaff HV, Tribouilloy C, Avierinos JF et al. Association between early surgical intervention vs watchful waiting and outcomes for mitral regurgitation due to flail mitral valve leaflets. JAMA 2013;310:609-16.

14. Suri RM, Topilsky Y. The role of cognitive dissonance in the management of functional tricuspid regurgitation at the time of degenerative mitral valve repair J Thorac Cardiovasc Surg. 2014;148:2810-2. 